\section{Cureus}

\title{
A Method for Combining Thin and Thick Malleable Titanium Mesh in the Repair of Cranial Defects
}

\author{
Darryl Lau ${ }^{1}$, Michael W. McDermott ${ }^{1}$ \\ 1. Department of Neurological Surgery, University of California, San Francisco \\ $\square$ Corresponding author: Darryl Lau, laud@neurosurg.ucsf.edu \\ Disclosures can be found in Additional Information at the end of the article
}

\section{Abstract}

Introduction: Cranial defects following the removal of tumor involved bone require repair and reconstruction for brain protection and cosmesis. A variety of autologous bone substrates and synthetic materials can be employed, alone or in combination. In this article, we describe the use of dual thin and thick titanium mesh, connected together using plate hardware, to repair a right frontotemporal sphenoidal bone defect following resection of a hyperostosing sphenoid wing meningioma.

Methods: Reconstruction of the pterion was done with a dual mesh cranioplasty. After replacement of the native orbitozygomatic and frontotemporal bone pieces, a piece of thinner mesh was molded to the pterional defect connecting the two bone pieces and re-creating the concave shape of the pterion below the superior temporal line. The circular area of the bony defect overlying the frontal and temporal lobes was supplemented by cutting and molding an additional piece of thicker mesh which was secured to the thinner mesh with burr hole cover sectors using rescue screws.

Results: A 30-year-old woman presented with painless proptosis and was found to have a hyperostosing right sphenoid wing meningioma. The patient underwent a frontotemporal orbitozygomatic craniotomy for tumor resection and extensive bony osteotomy. Repair and reconstruction of the cranial defect in the region were accomplished at the time of open operation using two thicknesses of mesh connected one to another with titanium plate pieces and rescue screws. The patient underwent gross total resection of the meningioma and near total resection of the soft tissue and bony components (Simpson Grade II). The external cosmetic results following the orbital-cranial reconstruction with the dual mesh technique was deemed "very good" by the surgeon and patient. Postoperative CT imaging demonstrated symmetric re-approximation of the shape of the pterion as compared to the opposite side.

Received 03/27/2015

Review began 03/29/2015

Review ended 04/19/2015

Published 05/04/2015

C) Copyright 2015

Lau et al. This is an open access article distributed under the terms of the Creative Commons Attribution License CC-BY 3.0., which permits unrestricted use, distribution, and reproduction in any medium, provided the original author and source are credited.
Conclusions: We present a method for connecting two titanium mesh sheets with available hardware to improve the strength in compression while maintaining the ability to mold thinner sheets as necessary for the best cosmetic results. This method is an option for coverage of bony defects in the region of the pterion for young, physically active patients providing them with additional mesh cranioplasty strength.

\section{Categories: Neurosurgery}

Keywords: cranial defect, titanium mesh, meningioma, pterion, cranioplasty, reconstruction 


\section{Cureus}

\section{Introduction}

The removal of tumor-involved bone in surgery for hyperostosing meningiomas of the sphenoid wing is necessary to improve the postoperative cosmetic result and to reduce the chance of tumor recurrence [1-3]. At times, hyperostosis associated with meningiomas can be extensive and involve a large portion of the skull; thus, after resection and osteotomy, defects can be large. One of the most challenging areas to reconstruct is the orbit and fronto-temporalsphenoidal region, given the bony shapes in the region are both concave and convex in close proximity [4]. It can be technically difficult to recreate these shapes after craniectomy to ensure a good cosmetic result while providing adequate strength for brain protection.

A variety of options exist for the surgeon to repair cranial defects of the pterion using both autologous and synthetic materials [5-9]. In this technical report, we describe a two-part mesh cranioplasty using a thin and thick mesh, connected one to another with existing hardware, to reconstruct the pterion. The first thinner mesh is molding over the curvilinear shapes of the pterion, connecting adjacent bone pieces for more rigid fixation. A template of the underlying skull defect is made and used to cut a thicker mesh, which can be secured with sector plate pieces and rescue screws to the molded thinner mesh.

\section{Technical Report}

\section{Double mesh cranioplasty: Surgical technique}

Following replacement of the orbital zygomatic osteotomy bone piece and the frontal temporal bone flap, a piece of thinner titanium mesh was molded by hand to replicate the concavity of the temporalis fossa while securing the two bone pieces together as well as to the bone near the floor of the middle fossa (Figure 1). 


\section{Cureus}

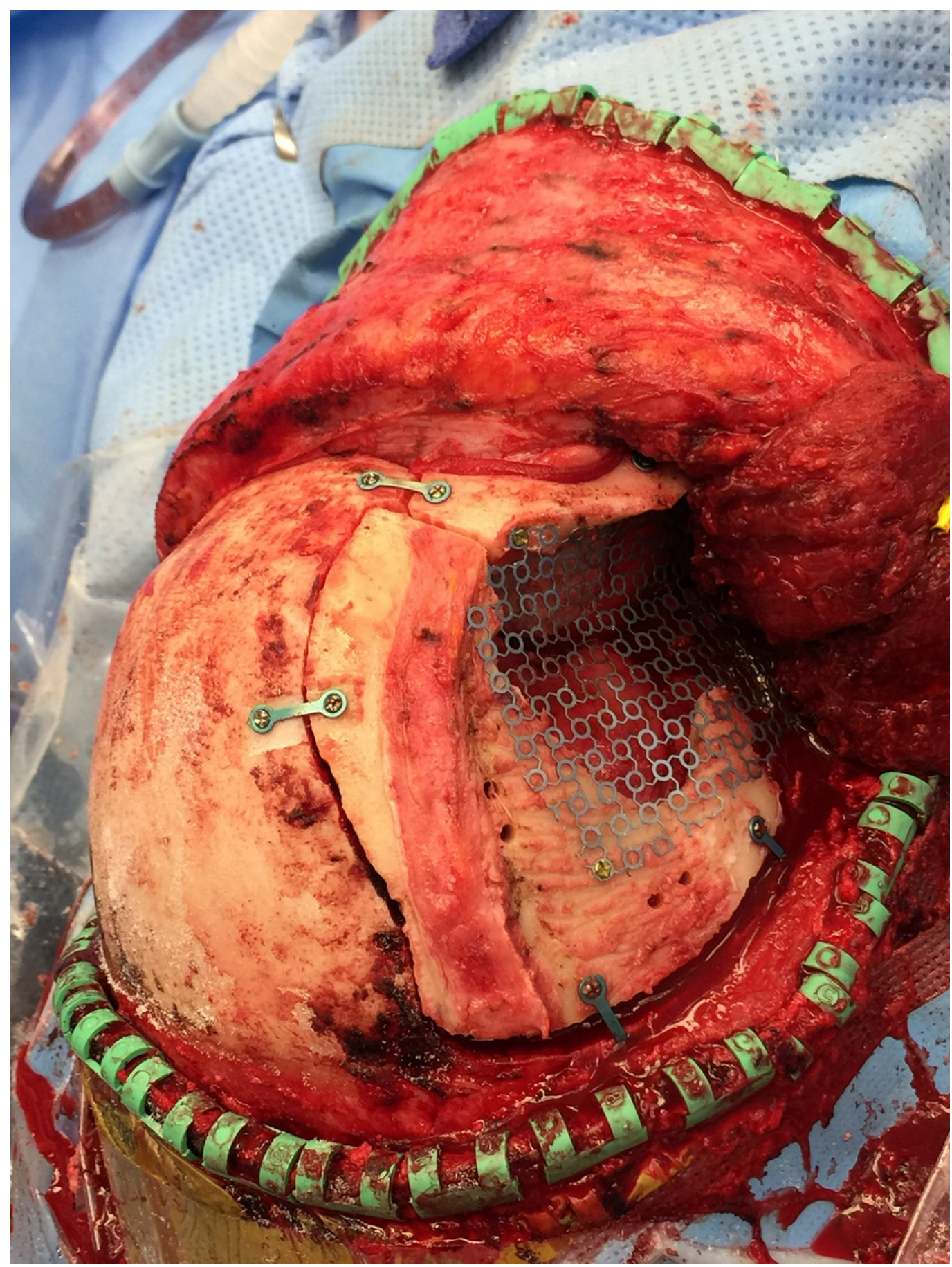

FIGURE 1: Thinner titanium mesh molded to replicate the concavity of the temporalis fossa

This molded mesh was then removed and the bone edges were marked with a surgical marker so that a template of the defect could be created by placing a piece paper over top and using this to outline the thicker piece of gold mesh to the appropriate size to cover just the bone defect (Figure 2). 


\section{Cureus}

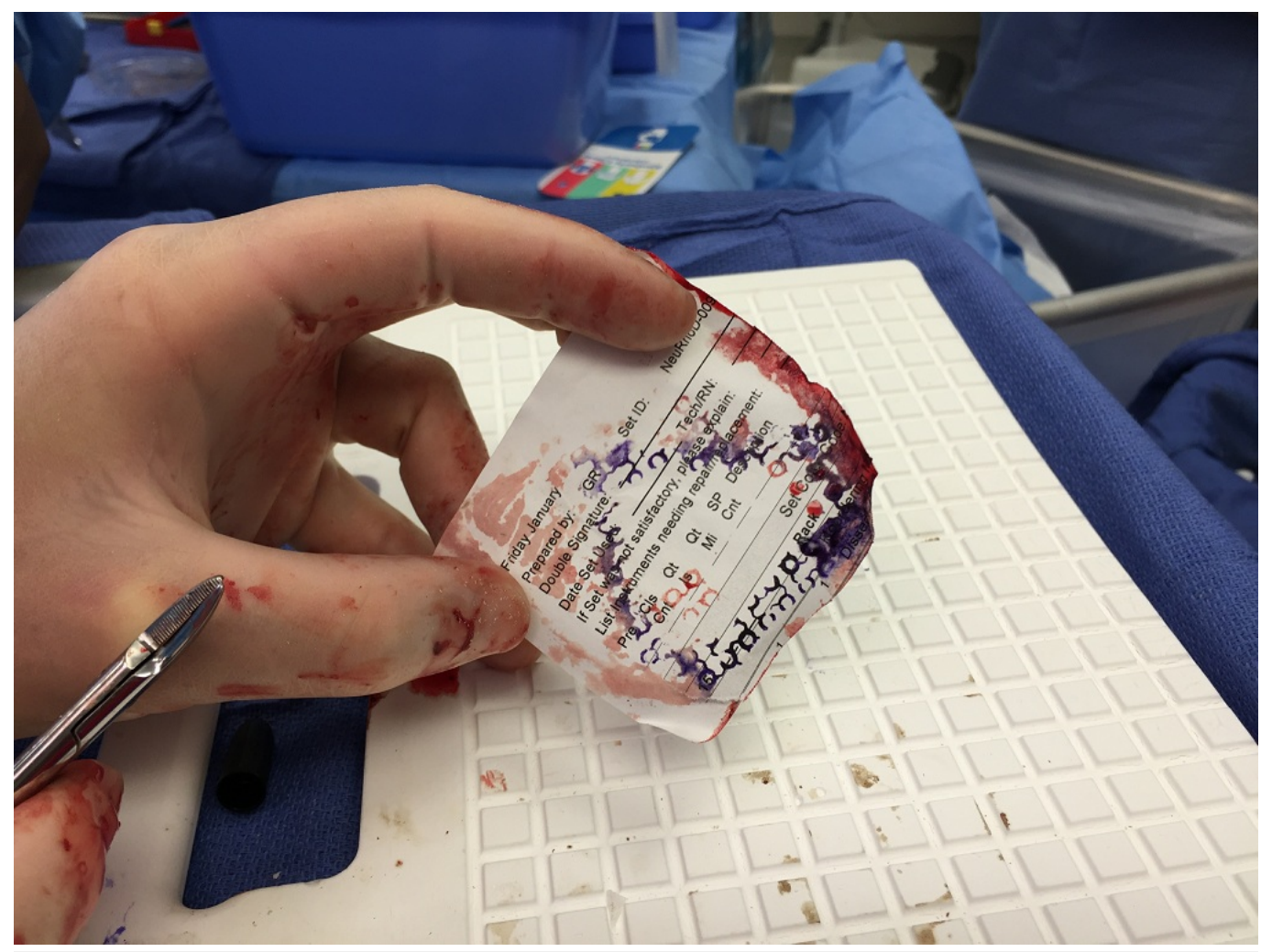

FIGURE 2: Outline of the bony defect for guide of thick mesh creation

The thicker mesh was then contoured by hand to try and match the shape of the thinner blue mesh. Next, a small burr hole cover was used as a donor for three small sectors; the sectors were broken off using a hinge motion until the metal fatigued at the bending point (Figures $3 A, 3 B$ ).
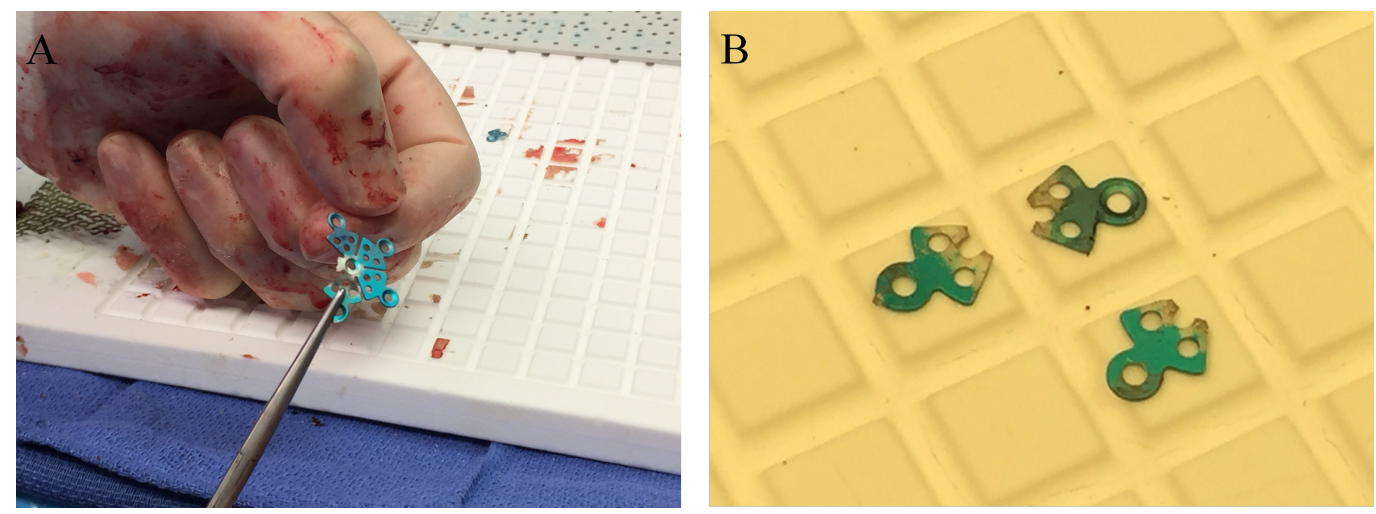

FIGURE 3: Obtaining sectors form burr-hole covers

The sector plates were placed behind the thinner mesh, and the plate holes (not the screw holes) were used to receive the larger rescue screws (Figures $4 A, 4 B$ ). 


\section{Cureus}
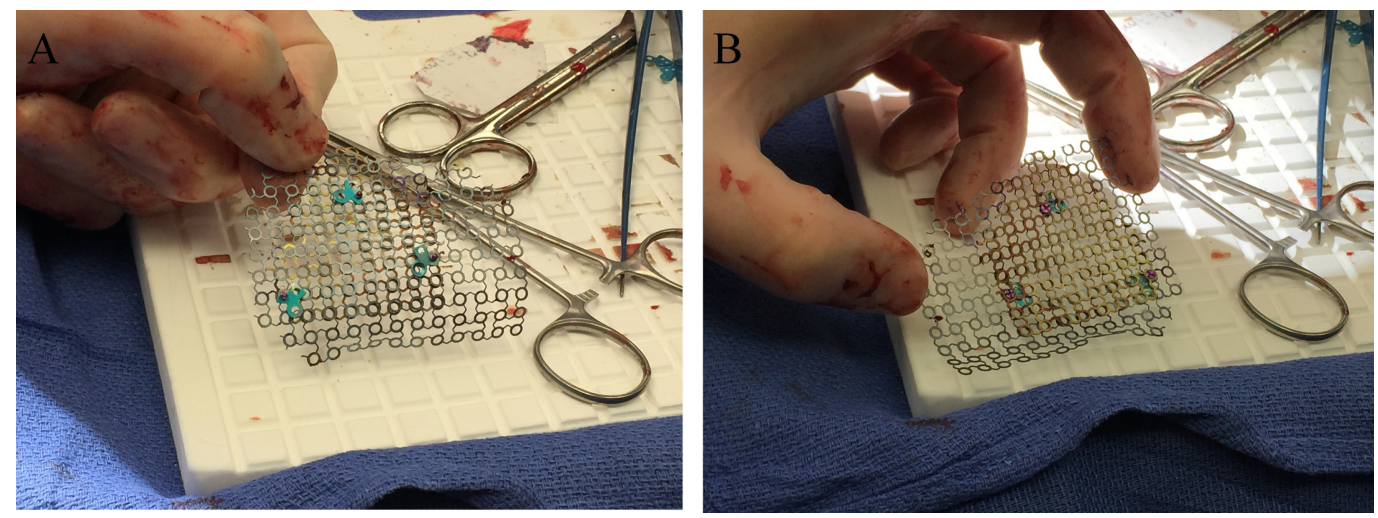

FIGURE 4: Securing thin and thick mesh with sector plates

The composite mesh cranioplasty was then re-secured to the surrounding skull using the initial thin mesh screw holes (Figure 5).

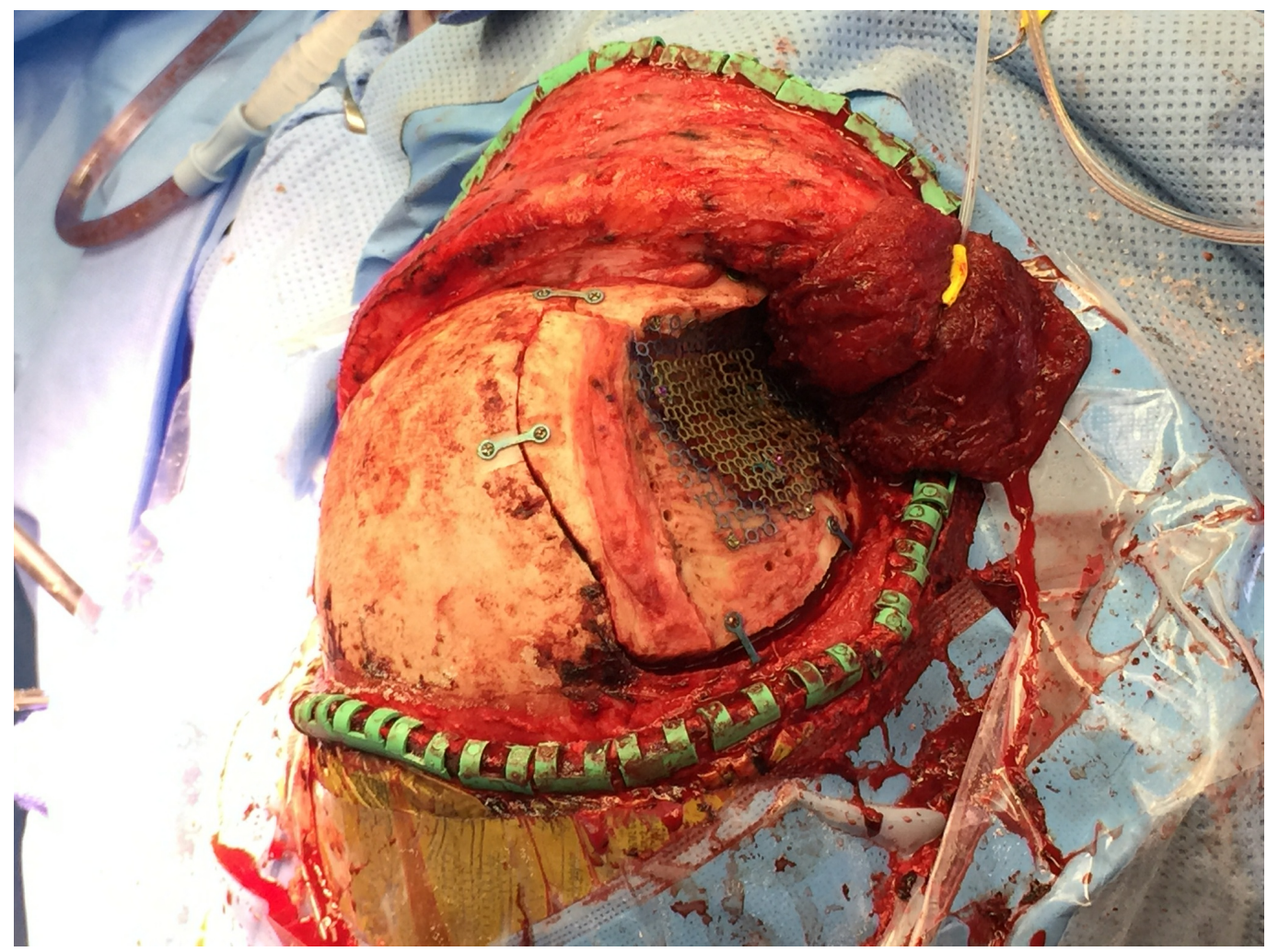

FIGURE 5: Re-implantation of dual mesh into defect site

\section{Outcome}

A 30-year-old female presented with painless right eye proptosis and was found to have a right middle fossa meningioma with extensive hyperostosis of surrounding bone with extension into the temporalis muscle (Figure 6). Informed patient consent was obtained for this study. 


\section{Cureus}
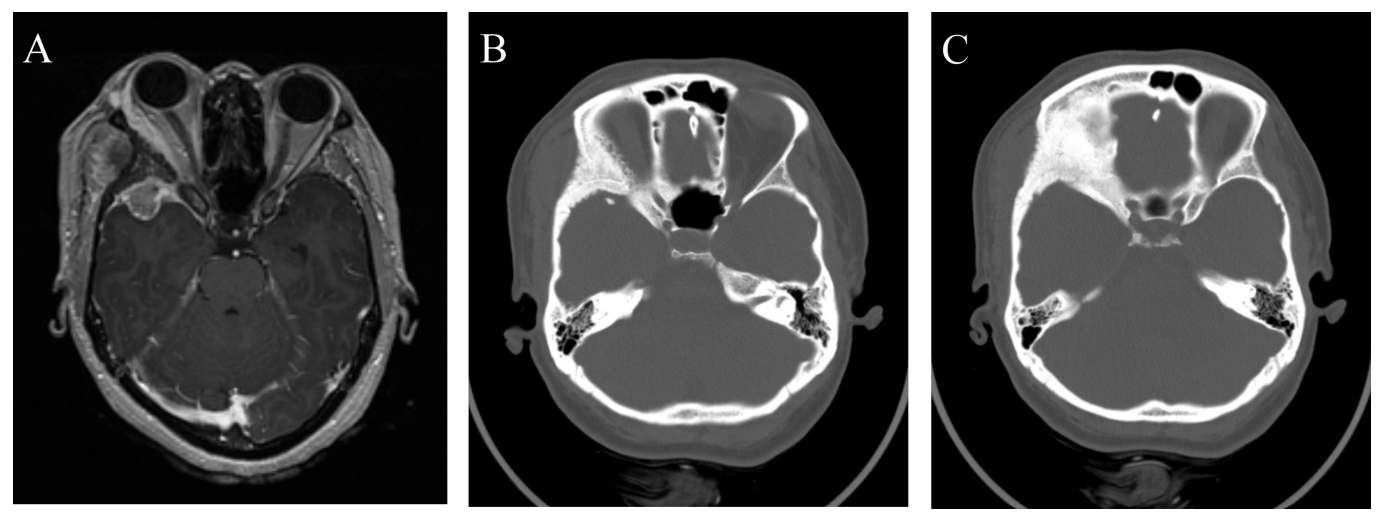

FIGURE 6: Preoperative MRI and CT imaging of right middle fossa meningioma

(A) Axial T1-weight MRI with contrast revealing a right middle fossa meningioma with associated hyperostosis of surrounding bone and invasion of the temporalis muscle. (B and C) Extensive bony hyperostosis of the right lateral orbit and pterion.

The patient was taken to the operating room for a right frontotemporal orbitozygomatic craniotomy for tumor resection. Pathology revealed a meningioma without high-grade features consistent with World Health Organization (WHO) Grade II. Given extensive hyperostosis and invasion of the temporalis muscle, osteotomy of surrounding bone left the patient with a large defect in the area of the orbit and pterion. We utilized the dual mesh technique to reconstruct the curvature of the pterion. Surgical removal of the soft tissue tumor and bone were near total (Figure 7). A postoperative CT scan demonstrated symmetric re-approximation of the shape of the pterion as compared to the opposite side on postoperative CT imaging (Figure 8). At followup, the external cosmetic results of the surgery were deemed "very good" by the surgeon and patient. 


\section{Cureus}

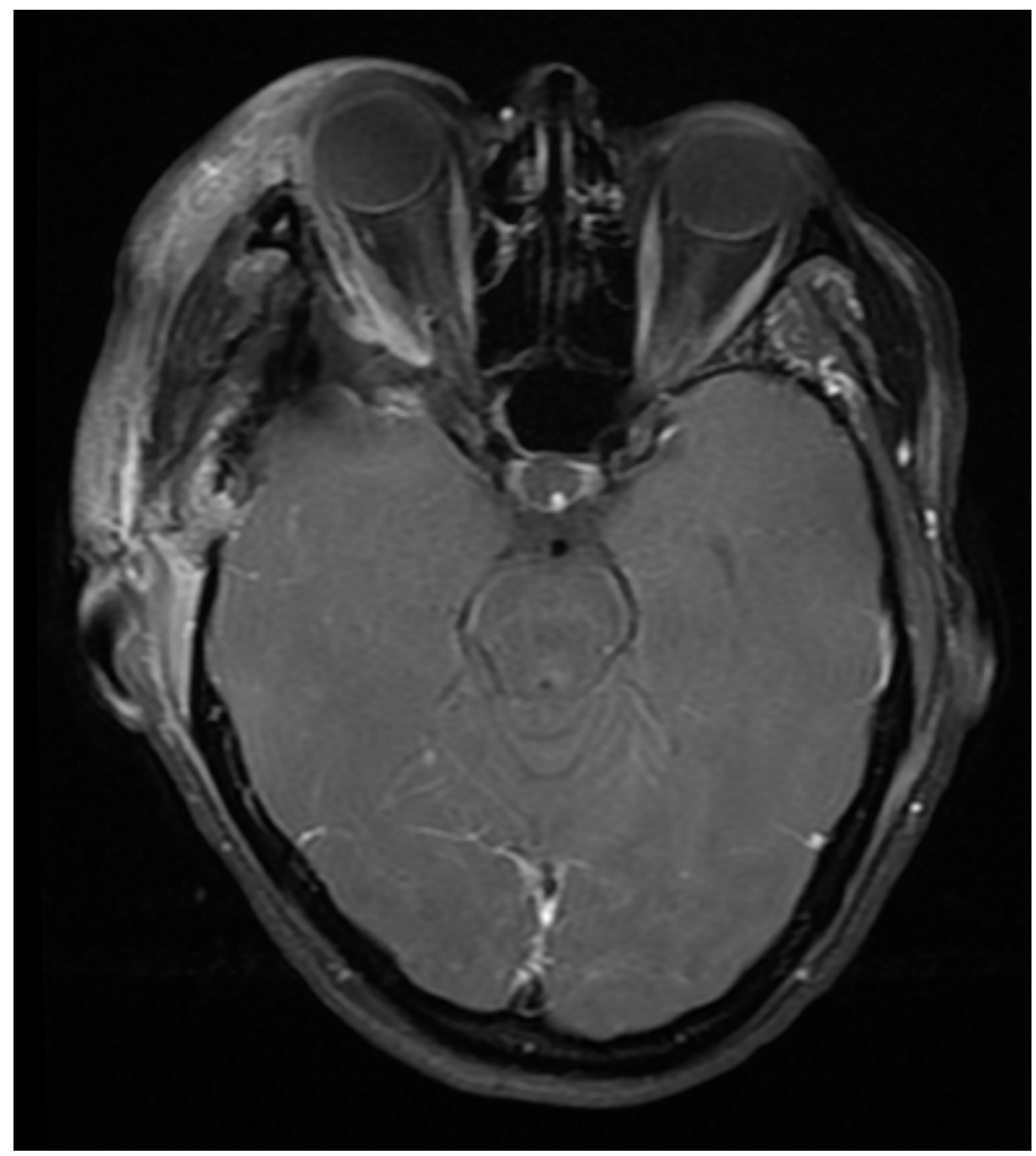

FIGURE 7: Postoperative MRI following right orbitozygomatic craniotomy for tumor resection

Axial T1-weighted MRI with contrast showing near total resection.
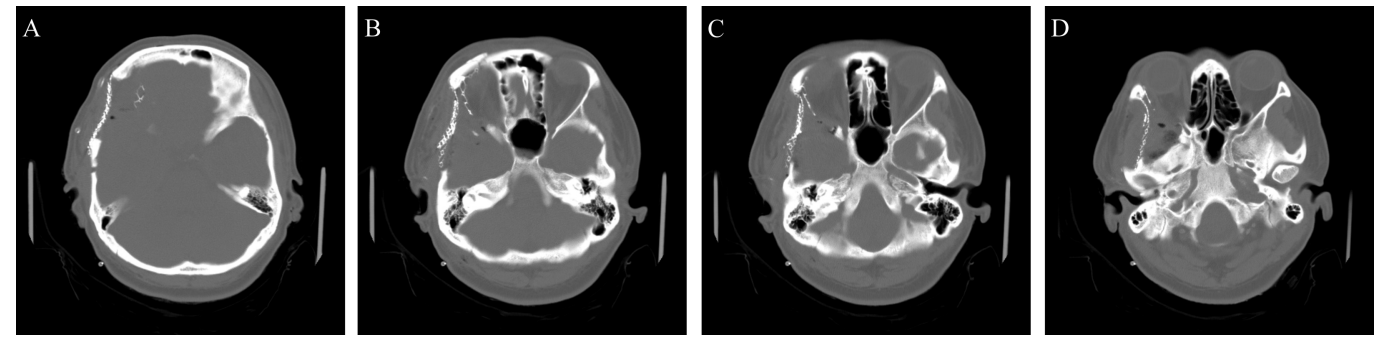

FIGURE 8: Postoperative CT following right orbitozygomatic craniotomy and cranial reconstruction 


\section{Discussion}

The challenges of meningioma surgery are often related to the location, vascularity, tumor consistency, and the presence of bony hyperostosis or invasion of surrounding tissue. It is well known that obtaining a more complete resection, according to the Simpson Grading System, is associated with lower rates of recurrence [3]. Therefore, in the setting of extensive bony and soft tissue involvement needing aggressive resection, patients are left with cranial defects requiring reconstruction. Proper reconstruction of the area around the orbit and pterion can be particularly difficult given the concave and convex nature of the area. The main objectives of cranioplasty are to promote primary wound healing, obliterate dead space, restore the normal barriers protecting the intracranial structures, and obtain a satisfactory cosmetic result.

Repairing and reconstructing a cranial defect during a patient's first operation for a tumor involving bone can be done with autologous bone or synthetic implants. Autologous bone can be harvested from adjacent calvarium (preferably from areas with similar contours) and implanted into the cranial defects [10-12]. The outcomes are good when performed by experienced surgeons. However, this technique is formidable and can be technically difficult. Harvest of the autologous bone requires additional bone removal, splitting of bone, shaping, and fixation of the harvested bone pieces to replicate the bone removed from the tumor site. The additional craniotomy site where the bone is harvested may increase the risk for complications, such as an epidural hematoma formation [13].

Synthetic materials can be used alone or in combination. Authors Bloch and McDermott described an in-situ cranioplasty where the abnormal bone could be shaped to a more normal contour and then used to mold mesh to the proper curvature before combining it with methyl methacrylate [14]. Methyl methacrylate is strong in compression but weak in tension while the reverse is true for titanium mesh. Combining the two together yields additional strength with properties of both elements, similar to the effects of adding rebar to concrete. Titanium mesh can be used alone and is supplied in varying thicknesses and sizes. Thicker mesh is difficult to mold to a multi-curved surface, and often the postoperative appearance on CT scans appears "flat" as compared to the intraoperative impression of the adequacy of shape.

Porous polyethylene implants are also available, with or without impregnated mesh [7, 15]. These implants may be weaker in compression than other single compound materials but are designed to promote tissue ingrowth and may reduce seroma formation [16]. Custom molded cranioplasty implants are made of metal or synthetic polymers but require a preexisting cranial defect for modeling. This would require a two-stage procedure; the first to excise tumor-involved bone with subsequent 3D imaging, computer-assisted design modeling, and creation of the cranioplasty. Next, a second stage procedure is needed for implantation of the custom implant.

In the dual mesh cranioplasty technique, thin mesh is used first to contour the desired shape more easily while the thicker mesh is used only over the bone defect site covering a smaller area without attempts to shape it to cover or recreate irregular surfaces. Connecting the two pieces together cannot be done without using some additional hardware, and to our knowledge, no plate manufacturer makes such an add-on component for this purpose. The senior author discovered by chance that the holes in the sectors of burr hole covers will accommodate a wider rescue screw in the same set, thus providing the "nut" (sector plate form burr hole cover) and "bolt" (rescue screw) for fixing the plates together. The resulting mesh cranioplasty is stronger in compression over the bony defect site and may provide additional protection for young, physically active patients who require craniectomy as part of their initial treatment. 


\section{Conclusions}

The composite dual mesh cranioplasty allows the maintenance of a cosmetically appropriate skull surface shape for the temporalis fossa, and connect the orbital osteotomy bone piece to the pterional bone flap, while adding strength in compression for the area of the skull defect over the frontal and temporal lobes. Importantly, it can be done during the first surgery, utilizing regularly available implants, and offers good cosmesis for the patient.

\section{Additional Information}

\section{Disclosures}

Human subjects: Consent was obtained by all participants in this study. Animal subjects: All authors have confirmed that this study did not involve animal subjects or tissue. Conflicts of interest: In compliance with the ICMJE uniform disclosure form, all authors declare the following: Payment/services info: All authors have declared that no financial support was received from any organization for the submitted work. Financial relationships: All authors have declared that they have no financial relationships at present or within the previous three years with any organizations that might have an interest in the submitted work. Other relationships: All authors have declared that there are no other relationships or activities that could appear to have influenced the submitted work.

\section{References}

1. Pieper DR, Al-Mefty O, Hanada Y, Buechner D: Hyperostosis associated with meningioma of the cranial base: Secondary changes or tumor invasion. Neurosurg. 1999, 44:742-746. 10.1097/00006123-199904000-00028

2. Kallio M, Sankila R, Hakulinen T, Jääskeläinen J: Factors affecting operative and excess longterm mortality in 935 patients with intracranial meningioma. Neurosurg. 1992, 31:2-12. 10.1227/00006123-199207000-00002

3. Simpson D: The recurrence of intracranial meningiomas after surgical treatment. J Neurol Neurosurg Psychiatry. 1957, 20:22-39.

4. Reinard K, Basheer A, Jones L, Standring R, Lee I, Rock J: Surgical technique for repair of complex anterior skull base defects. Surg Neurol Int. 2015, 6:20. 10.4103/2152-7806.151259

5. Matsumoto K, Akagi K, Abekura M, Ohkawa M, Tasaki O, Tomishima T: Cosmetic and functional reconstruction achieved using a split myofascial bone flap for pterional craniotomy. Technical note. J Neurosurg. 2001, 94:667-670. 10.3171/jns.2001.94.4.0667

6. Sakata Y, Hadeishi H, Moroi J: Cosmetic frontotemporal craniotomy using an osteotome: technical note. Neurol Med Chir (Tokyo). 2013, 53:635-637. 10.2176/nmc.tn2012-0347

7. Choudhry OJ, Christiano LD, Arnaout O, Adel JG, Liu JK: Reconstruction of pterional defects after frontotemporal and orbitozygomatic craniotomy using Medpor Titan implant: cosmetic results in 98 patients. Clin Neurol Neurosurg. 2013, 115:1716-1720.

10.1016/j.clineuro.2013.03.014

8. Jung SH, Ferrer AD, Vela JS, Granados FA: Spheno-orbital meningioma resection and reconstruction: the role of piezosurgery and premolded titanium mesh. Craniomaxillofac Trauma Reconstr. 2011, 4:193-200. 10.1055/s-0031-1286113

9. Sanada Y, Fujinaka T, Yoshimine T, Kato A: Optimal reconstruction of the bony defect after frontotemporal craniotomy with hydroxyapatite cement. J Clin Neurosci. 2011, 18:280-282. 10.1016/j.jocn.2010.03.045

10. Papay FA, Zins JE, Hahn JF: Split calvarial bone graft in cranio-orbital sphenoid wing reconstruction. J Craniofac Surg. 1996, 7:133-139.

11. Agrawal A, Baisakhiya N, Bhola N: Split calvarial graft to repair the large frontal bone defect. J Maxillofac Oral Surg. 2010, 9:166-169. 10.1007/s12663-010-0048-1

12. Agrawal A, Garg LN: Split calvarial bone graft for the reconstruction of skull defects . J Surg Tech Case Rep. 2011, 3:13-16. 10.4103/2006-8808.78465

13. Young VL, Schuster RH, Harris LW: Intracerebral hematoma complicating split calvarial bonegraft harvesting. Plast Reconstr Surg. 1990, 86:763-765. 


\section{Cureus}

14. Bloch O, McDermott MW: In situ cranioplasty for hyperostosing meningiomas of the cranial vault. Can J Neurol Sci. 2011, 38:59-64. 10.1017/S0317167100011082

15. Wang JC, Wei L, Xu J, Liu JF, Gui L: Clinical outcome of cranioplasty with high-density porous polyethylene. J Craniofac Surg. 2012, 23:1404-1406. 10.1097/SCS.0b013e31825e3aeb

16. Couldwell WT, Chen TC, Weiss MH, Fukushima T, Dougherty W: Cranioplasty with the Medpor porous polyethylene flexblock implant. Technical note. J Neurosurg. 1994, 81:483486. 10.3171/jns.1994.81.3.0483 